\title{
Involvement of pCREB Expression in Inhibitory Effects of Coptis japonica on Morphine-induced Psychological Dependence
}

\author{
Seung-Hwan Kwon, Ri-Ra HA, Seok-Yong Lee and Choon-Gon JANG* \\ Department of Pharmacology, College of Pharmacy, Sungkyunkwan University, Suwon 440-746, Republic of Korea
}

(Received April 28, 2008; Accepted June 11, 2008)

\begin{abstract}
Morphine is a potent analgesic with significant abuse potential, because of drug craving and psychological dependence. It is reported that repeated treatment of morphine can produce conditioned place preference (CPP) showing a reinforcing effect in mice. Previously, we have reported the inhibitory effect of the methanolic extract of Coptis japonica (MCJ) on morphine-induced CPP in mice. The present study was employed whether p-CREB expression is involved in the inhibitory effect of MCJ on the morphine-induced CPP in the mouse hippocampus. Repeated administration of MCJ $100 \mathrm{mg} / \mathrm{kg}$ inhibited morphine-induced CPP. Expression of p-CREB was increased in the dentate gyrus of the hippocampus that had undergone morphineinduced CPP. This increase of expression was significantly inhibited by administration of MCJ $100 \mathrm{mg} / \mathrm{kg}$, compared to the morphine control group. Taken together, these results suggest that MCJ inhibits morphine-induced CPP through the regulation of $\mathrm{p}$-CREB expression in the mouse dentate gyrus of the hippocampus.
\end{abstract}

Keywords: Conditioned place preference; Coptis japonica; p-CREB; Immunohistochemistry

\section{INTRODUCTION}

Morphine is a useful analgesic, but considered an addictive drug because drug-craving and psychological dependence. A single treatment with morphine in animals produces hyperactivity and stereotyped behaviors (Shuster et al., 1963). Chronic treatment with morphine leads to the development of conditioned place preference (CPP) (Mucha et al., 1982; Bardo et al., 1984). The CPP paradigm has been used as a model for studying the reinforcing effect of drugs with dependence liability (van der Kooy, 1987). It has been reported that drug addiction is strongly associated with learning and memory (Robbins and Everiff, 1999; Berke and Hyman, 2000). Learning and memory depend on activation of the transcription factor CAMP-response element binding protein (CREB). They are accompanied by alterations in neural plasticity at glutamate synapses. CREB, a transcription factor in particular has been implicated in opiates addiction (Nestler, 2001) and CPP (Gao et al., 2003). This result suggests that CREB may play an important role in the development of morphine-induced CPP.

\footnotetext{
${ }^{*}$ Corresponding author

Tel: +82-31-290-7780,

E-mail: jang@skku.ac.kr
}

Coptis japonica is a well-known, traditional oriental medicine. It has a wide range of pharmacological and biological activities, including anti-inflammatory (Ivanovska and Philipov, 1996) and antimicrobial (Schmeller et al., 1997) effects. Hsieh et al. (2000) have reported that Coptis chinese has an ameliorating effect on scopolamineinduced amnesia in rats. It is reported that protoberberine alkaloids from the roots of Coptis japonica inhibit the catecholamine biosynthesis in PC12 cells (Lee and Kim, 1996). Recently, it is reported that coptisine, a major component of Coptis japonica, inhibits MAO-A activity in the mouse whole brain (Ro et al., 2001). We, therefore, presumed that inhibitors of catecholamine biosynthesis or MAO-A inhibitors could be a candidate for the treatment of psychological dependence or withdrawal syndrome, respectively. Previously we have reported that inhibitory effects of MCJ on the CPP induced by morphine. This inhibition was involved in the inhibition of increase in the c-fos expression of morphine CPP mouse brains. This result implicates that MCJ might regulate other gene expression, such as CREB which is implicated in opiates addiction (Nestler, 2001; Hyman, 1996). Therefore, the present experiments were undertaken to determine whether p-CREB expression is involved in the inhibitory effects of MCJ on the CPP induced by morphine to examine the neurochemical mechanisms. 


\section{MATERIALS AND METHODS}

\section{Animals and drugs}

Male ICR mice (MJ Ltd., Seoul, Korea) weighing 18$24 \mathrm{~g}$ were used. They were housed 10 mice to a cage with water and food available ad libitum under an artificial $12 \mathrm{hr}$ light/dark cycle (light at 7:00 a.m.) and constant temperature $\left(22 \pm 2^{\circ} \mathrm{C}\right)$.

The drug used was morphine hydrochloride (Je-il Pharm. Co., Seoul, Korea). MCJ was obtained from the Institute of Natural Medicine, Hallym University (Chuncheon, Korea). All drugs were dissolved in physiological saline just prior to the experiment.

\section{Measurement of morphine-induced CPP Apparatus}

The CPP apparatus made according to our previously reported methods (Kim et al., 1996), consisted of two square-based Plexiglas compartments $(15 \times 15 \times 15 \mathrm{~cm})$, one with white walls and the other with black walls which could be closed by guillotine doors. To provide a tactile difference between the compartments floors, the white compartment had a metal grid floor and the black compartment had a wire mesh floor. Removal of the guillotine doors during the pre-testing and the final testing phases allowed animals to freely access to both compartments, and the time spent by the mice in each of the two compartments was recorded for 15 min using a video camera. All conditioning or test sessions were conducted under ambient light (20-30 Lux).

\section{Procedures for place conditioning}

Preliminary data from our laboratory indicated that naive mice spent more time in the black compartment than in the white compartment when given free access to the entire apparatus for $15 \mathrm{~min}$. Thus, to establish conditioning, we paired the morphine-administered mice with the initially non-preferred white compartment. The control mice received a subcutaneous injection of saline immediately before exposure to the black compartment. Morphine $(5 \mathrm{mg} / \mathrm{kg}$, s.c.) was given just before the mice were placed in the white compartment. To test the effect of MCJ (100 mg/kg, p.o.) alone or in combination with morphine, MCJ was administered $1 \mathrm{hr}$ prior to saline or morphine injections, respectively.

Pre-testing phase: On day 1, the mice were preexposed to the test apparatus for $5 \mathrm{~min}$. The guillotine doors were raised and each animal was allowed to move freely between the two compartments. On day 2, baseline preference was determined for the non-preferred side vs. the preferred side for $15 \mathrm{~min}$.

Conditioning phase: On days 3, 5, 7 and 9, the mice were injected with drug before confinement in the white compartment, non-preferred side, for $40 \mathrm{~min}$. On days 4, 6,8 and 10, the mice were injected with saline before confinement in the black compartment, preferred side, for 40 min.

Testing phase: On day 11, the guillotine doors were raised, the mice were placed in the tunnel in the central part of the apparatus, and the time spent by the mice in the two compartments was recorded for $15 \mathrm{~min}$.

Place preference data were expressed as the difference between times spent in the testing and pre-testing phases in the white compartment. We also measured the number of crossings between white and black compartments in the testing phase.

\section{Measurement of Immunohistochemistry \\ Brain section}

Mice were anesthetized with sodium pentobarbital and perfused transcardially with $4 \%$ paraformaldehyde in $0.1 \mathrm{M}$ phosphate buffer ( $\mathrm{pH} 7.4), 24 \mathrm{~h}$ after the morphineinduced CPP paradigm. Mouse brains were removed and brain samples were sectioned coronally $(45 \mu \mathrm{m})$ on a freezing microtome at $-20^{\circ} \mathrm{C}$.

\section{Immunohistochemistry for $\mathrm{p}$-CREB expression}

Floating sections of brains were processed as described previously by Baker and Farbman (1993). Briefly, the immunocytochemical procedure started with rinsing twice in $0.1 \mathrm{M}$ PBS, followed by $2 \mathrm{~h}$ incubation to suppress non-specific absorption in the preincubation solution (0.1M PBS containing $0.2 \%$ Triton X-100, 1\% bovine serum albumin). To demonstrate p-CREB immunoreactivity, we used the primary antiserum: rabbit anti-pCREB (1:1000, Santa Cruz Biotechnology, Inc) in a solution of $0.5 \%$ bovine albumin and preservative sodium azide in 0.1M PBS. The sections were incubated in primary antiserum for $16 \mathrm{~h}$ at room temperature. On the following day, sections were incubated for $1 \mathrm{~h}$ in biotinylated rabbit secondary antibody obtained from Vector laboratories. After a short rinse with PBS, they were reacted by using the avidin-biotin peroxidase complex (ABC) method (Vector), and washed twice in 0.1M PBS. The antigens were visualized by the solution containing $0.02 \% 3,3-$ diaminobenzidine tetrahydrochloride (DAB) and $0.0045 \%$ $\mathrm{H}_{2} \mathrm{O}_{2}$ at room temperature.

\section{Statistics}

The data were expressed as mean \pm S.E.M. Statistical 


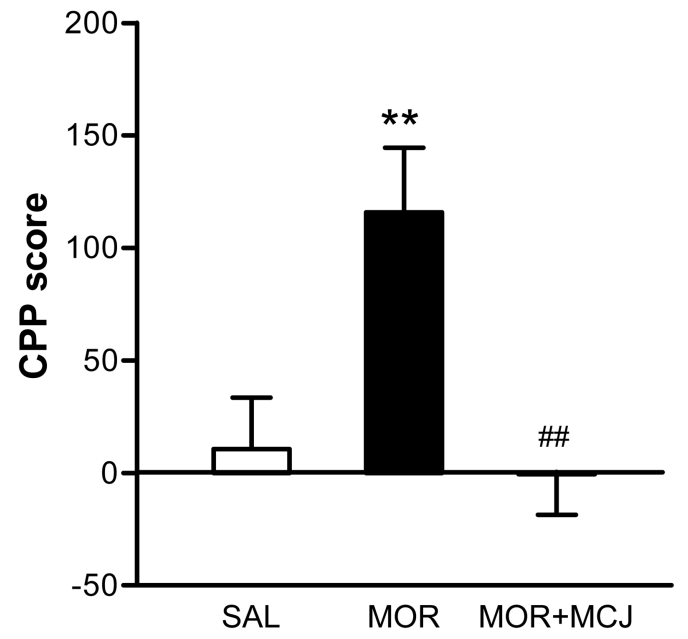

Fig. 1. Effect of MCJ on morphine-induced psychological dependence in mice. MCJ (100 mg/kg, p.o.) was administered $1 \mathrm{hr}$ prior to the injection of morphine $(5 \mathrm{mg} / \mathrm{kg})$. In the conditioning phase, the mice were injected with saline or morphine just before being confined in the black or white compartment for 40 min every day over 8 days. The scores were calculated from the differences between the testing and pre-testing phases $(15 \mathrm{~min})$ in the white compartment. ${ }^{* *} P<0.01$, compared with that of the saline group. ${ }^{\#} \mathrm{P}<0.01$, compared with that of the morphine group. Abbreviations: SAL, saline; MOR, morphine; MCJ, methanolic extract of Coptis japonica.

analysis was carried out by one-way analysis of variance (ANOVA). In the case of significant variation, the individual values were compared by the Student Newman-Keuls test. The criterion for significance was $p<0.05$ in all statistical analyses.

\section{RESULTS}

\section{Effects of MCJ on morphine-induced CPP}

As reported previously, we confirmed that the morphine-treated group showed a significant psychological dependence producing CPP effect $(p<0.01$, Fig. 1). The group pretreated with $100 \mathrm{mg} / \mathrm{kg}$ of MCJ showed a significant inhibition of $5 \mathrm{mg} / \mathrm{kg}$ of morphine-induced CPP yielding a time difference between that spent in the testing and pre-testing phases in the white compartment of $0.6 \mathrm{sec}$, which was $116.5 \mathrm{sec}$ less than the $115.9 \mathrm{sec}$ of the morphine control group $(\mathrm{p}<0.01)$.

\section{Effects of MCJ on crossing numbers in morphine- induced CPP mice}

As reported previously, we confirmed that there was no significant difference in crossing numbers between the morphine treatment and saline groups in the crossing numbers between white and black compartments in the

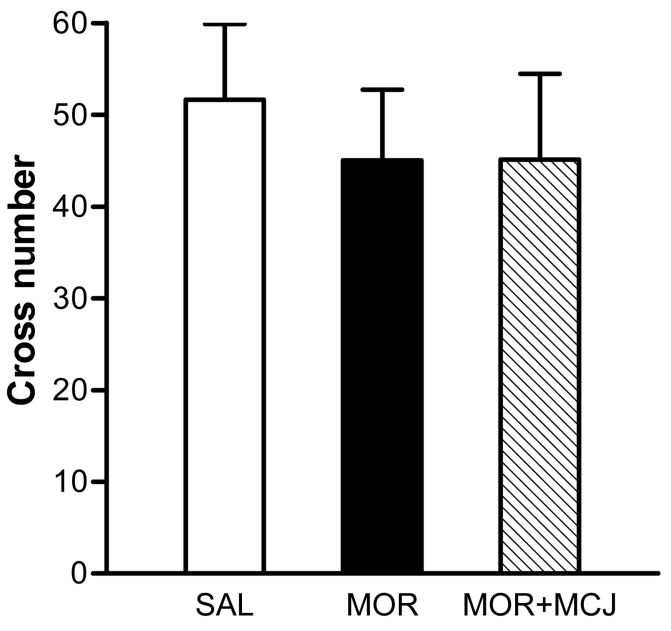

Fig. 2. Effects of MCJ on numbers of crossing in morphineinduced psychological dependence in mice.

MCJ (100 mg/kg, p.o.) was administered $1 \mathrm{hr}$ prior to the injection of morphine $(5 \mathrm{mg} / \mathrm{kg})$. In the conditioning phase, the mice were injected with saline or morphine just before being confined in the black or white compartment for 40 min every day over 8 days. The numbers of crossing between white and black compartments during the testing phase were counted (15 min).
Saline

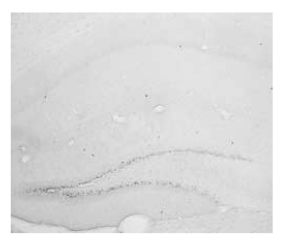

Morphine

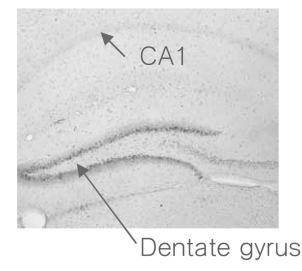

Morphine+MCJ

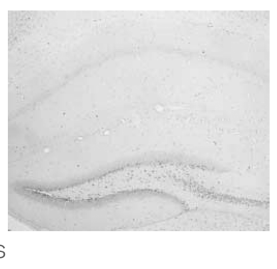

Fig. 3. Effects of MCJ on p-CREB expression in morphineinduced psychological dependence in mice. Images showing the expression of $\mathrm{p}$-CREB immunoreactivity are in the dentate gyrus of the hippocampus along the rostro-caudal axis. MCJ $100 \mathrm{mg} / \mathrm{kg}$ was administered to mice $1 \mathrm{~h}$ before morphine treatment $(5 \mathrm{mg} / \mathrm{kg})$, according to the CPP schedule. Mice were sacrificed at $24 \mathrm{~h}$ after the CPP schedule and brain samples were sectioned at a thickness of $45 \mu \mathrm{m}$.

testing phase (Fig. 2). Also, there was no significant change in crossing numbers in the MCJ pretreatment group.

\section{Effects of MCJ on p-CREB expression in morphine- induced CPP mice}

The p-CREB expression was markedly increased in the dentate gyrus of the hippocampus of mice with morphine-induced CPP (Fig. 3). However, pretreatment with $100 \mathrm{mg} / \mathrm{kg}$ of MCJ inhibited the increased p-CREB expression in the dentate gyrus of the hippocampus of 
the morphine-induced CPP mouse which was measured in this study.

\section{DISCUSSION}

Morphine indirectly stimulates the dopaminergic neurons by inhibiting GABAergic neurons (Johnson and North, 1992; Klitenick et al., 1992). Morphine can activate mesolimbic DA release resulting in an activation of the mesolimbic DA pathway (Koob and Bloom, 1988; Wise and Rompre, 1989). The activation of the dopaminergic system appears to be involved in the rewarding effects to morphine (Wise and Bozarth, 1987; Wise and Rompre, 1989). Accumulated evidence has suggested that the dopaminergic system plays a key role in the reinforcing effects of morphine (Bozarth, 1986). However, the molecular mechanisms underlying morphine rewarding effects are not fully understood. Recently, several researchers have been focused on the gene expressions in specific brain regions of morphine dependent mice. It is reported that morphine and other addictive drugs induce the immediate-early gene c-fos in the nucleus accumbens and dorsal medial striatum (Graybiel et al., 1990; Young et al., 1991). It is proposed that c-fos expression in the nucleus accumbens is necessary for the acquisition, but not the expression, of morphine-induced CPP (Tolliver et al., 2000). Furthermore, we have previously reported that c-fos expression was increased in the parietal cortex, piriform cortex, striatum, nucleus accumbens, and hippocampus of the mouse brain, which produced morphine-induced CPP (Lee et al., 2003). A transcription factor, CREB, in particular has been implicated in opiates addiction (Nestler, 2001) and CPP (Gao et al., 2003) because its activation was a consequence of upregulation of the CAMP pathway, one of the well established adaptations to drug abuse (Hyman, 1996).

In present experiment, $\mathrm{p}$-CREB expression is increased in morphine-induced CPP mouse hippocampus. Treatment with MCJ inhibited the increase of $p$-CREB expression in morphine-induced CPP mouse hippocampus. CERB has been implicated in the formation of long-term memory and CREB-mediated transcription in the hippocampus is related to learning and memory (Deisseroth et al., 1996). Also it is well known that hippocampus play a key role in tolerance, dependence, and withdrawal (Fan et al., 1999; Lou et al., 1999). The development of CPP is deeply related to a kind of the memory process combined with environmental cue and drug. Therefore, our result suggests that MCJ inhibits morphine-induced CPP via of the $p$-CREB expression induced by morphine in these brain regions. It has been reported that berberine, palmatine, and protoberberine alkaloids from the roots of Coptis japonica, decrease dopamine content by reducing the tyrosine hydroxylase activity in PC12 cells (Shin et al., 2000). It is also reported that berberine and palmatine also inhibit bovine adrenal tyrosine hydroxylase (Lee and Zhang, 1996; Lee et al., 1996). Furthermore, berberine, a major component of Coptis japonica, inhibited morphineinduced CPP in mice (Yoo et al., 2006). Therefore, further studies are needed to elucidate the molecular mechanisms and involvement of active components in the inhibitory effect of MCJ on morphine-induced CPP. Taken together, it is concluded that MCJ, a methanolic extract of Coptis japonica, may be useful for the prevention and treatment of morphine-induced psychological dependence.

\section{ACKNOWLEDGEMENTS}

This work was supported by grant (M103KV01001308K2201-01310) from the Brain Research Center of the $21^{\text {st }}$ Century Frontier Research Program funded by the Ministry of Science and Technology, Republic of Korea.

\section{REFERENCES}

Baker, H. and Farbman, A.I. (1993) Olfactory afferent regulation of the dopamine phenotype in the fetal rat olfactory system. Neuroscience 52, 115-134.

Bardo, M.T., Miller, J.S., and Neisewander, J.S. (1984) Conditioned place preference with morphine: The effect of extinction training on the reinforcing CR. Pharmacol. Biochem. Behav. 21, 545-549.

Berke, J.D. and Hyman, S.E. (2000) Addiction, dopamine, and the molecular mechanisms of memory. Neuron 25, 515-532.

Bozarth, M.A. (1986) Neural basis of psychomotor stimulant and opiate reward: evidence suggesting the involvement of a common dopaminergic system. Behav. Brain Res. 22, 107116.

Deisseroth, K, Bito, H, and Tsien, R.W. (1996) Signaling from synapse to nucleus: postsynaptic CREB phosphorylation during multiple forms of hippocampal synaptic plasticity. Neuron 16, 89-101.

Fan, G.H., Wang, L.Z., Quu, H.C., Ma, L., and Pei, G. (1999) Inhibition of calcium/calmodulin-dependent protein kinase II in rat hippocampus attenuates morphine tolerance and dependence. Mol. Pharmacol. 56, 39-45.

Gao, C., Che, L.W., Chen, J., Xu, X.J., and Chi, Z.Q. (2003) Ohmefentanyl stereoisomers induce changes of CREB phosphorylation in hippocampus of mice in conditioned place preference paradigm. Cell Res. 13, 29-34.

Graybiel, A.M., Moratalla, R., and Robertson, H.A. (1990) Amphetamine and cocaine induce drug-specific activation of the c-fos gene in striosome-matrix compartments and limbic 
subdivisions of the striatum. Proc. Natl. Acad. Sci. USA 87, 6912-6916.

Hsieh, M.T., Peng, W.H., Wu, C.R., and Wang, W.H. (2000) The ameliorating effects of the cognitive-enhancing Chinese herbs on scopolamine-induced amnesia in rats. Phytotherapy Res. 14, 375-377.

Hyman, S.E. (1996) Shaking out the cause of addiction. Science 273, 611-612.

Ivanovska, N. and Philipov, S. (1996) Study on the anti-inflammatory action of Berberis vulgaris root extract, alkaloid fractions and pure alkaloids. Int. J. Immunopharmacol. 18, 553561.

Johnson, S.W. and North, R.A. (1992) Opioids excite dopamine neurons by hyperpolarization of local interneurons. J. Neurosci. 12, 483-488.

Kim, H.S., Jang, C.G., and Park, W.K. (1996) Inhibition by MK801 of morphine-induced conditioned place preference and postsynaptic dopamine receptor supersensitivity in mice. Pharmacol. Biochem. Behav. 55, 11-17.

Klitenick, M.A., DeWitte, P., and Kalivas, P.W. (1992) Regulation of somatodendritic dopamine release in the ventral tegmental area by opioids and GABA: an in vivo microdialysis study. J. Neurosci. 12, 2623-2632.

Koob, G.F. and Bloom, F.E. (1988) Cellular and molecular mechanisms of drug dependence. Science 242, 715-723.

Lee, M.K. and Kim, H.S. (1996) Inhibitory effects of protoberberine alkaloids from the roots of Coptis japonica on catecholamine biosynthesis in PC12 cells. Planta Med. 62, 31-34.

Lee, M.K. and Zhang, Y.H. (1996) Inhibition of tyrosine hydroxylase by berberine. Med. Sci. Res. 24, 561-562.

Lee, M.K., Zhang, Y.H., and Kim, H.S. (1996) Inhibition of tyrosine hydroxylase by palmatine. Arch. Pharm. Res. 19, 258-260.

Lee, S.Y, Song, D.K, and Jang, C.G. (2003) Effects of Coptis japonica on morphine-induced conditioned place preference in mice. Arch Pharm Res. 26, 540-544.

Lou, L.G., Zhou, T.H., Wang, P., and Pei, G. (1999) Modulation of $\mathrm{Ca}^{2+} /$ Calmodulin-dependent protein kinase II activity by acute and chronic morphine administration in rat hippocampus: differential regulation of $\mathrm{a}$ and $\mathrm{b}$ isoforms. Mol. Pharmacol. 55, 557-563.
Mucha, R.F., van der Kooy, D., O'Shaughnessy, M., and Bucenieks, P. (1982) Drug reinforcement studied by the use of place conditioning in rat. Brain Res. 243, 91-105.

Nestler, E.J. (2001) Molecular basis of long-term plasticity underlying addiction. Nat. Rev. Neurosci. 2, 119-128.

Ro, J.S., Lee, S.S., Lee, K.S., and Lee, M.K. (2001) Inhibition of type A monoamine oxidase by coptisine in mouse brain. Life Sci. 70, 639-645.

Robbins, T.W. and Everiff, B.J. (1999) Drug addiction: bad habits add up. Nature 398, 567-570.

Schmeller, T., Latz-Bruning, B., and Wink, M. (1997) Biochemical activities of berberine, palmatine and sanguinarine mediating chemical defense against microorganisms and herbivores. Phytochemistry 44, 257-266.

Shin, J.S., Kim, E.I., Kai, M., and Lee, M.K. (2000) Inhibition of dopamine biosynthesis by protoberberine alkaloids in PC12 cells. Neurochem. Res. 25, 363-368.

Shuster, L., Hannam, R.V., and Boyle, W.E.Jr. (1963) A simple method for producing tolerance to dihydromorphine in mice. J. Pharmacol. Exp. Ther. 140, 149-153.

Tolliver, B.K., Sganga, M.W., and Sharp, F.R. (2000) Suppression of $\mathrm{c}$-fos induction in the nucleus accumbens prevents acquisition but not expression of morphine-conditioned place preference. Eur. J. Neurosci. 12, 3399-3406.

van der Kooy, D. (1987) Place conditioning: a simple and effective method for assessing the motivational properties of drugs. In Methods of Assessing the Reinforcing Properties of Abuse Drugs (M.A. Bozarth, Ed.), pp. 229-240. Springer, New York.

Wise, R.A. and Rompre, P.P. (1989) Brain dopamine and reward. Ann. Rev. Psychol. 40, 191-225.

Wise, R.A. and Bozarth, M.A. (1987) A psychomotor stimulant theory of addiction. Psychol. Rev. 94, 469-492.

Yoo, J.H., Yang, E.M., Cho, J.H., Lee, J.H., Jeong, S.M., Nah, S.Y., Kim, H.C., Kim, K.W., Kim, S.H., Lee, S.Y., and Jang, C.G., (2006) Inhibitory effects of berberine against morphineinduced locomotor sensitization and analgesic tolerance in mice. Neuroscience 142, 953-961.

Young, S.T., Porrino, L.J., and ladarola, M.J. (1991) Cocaine induces striatal c-fos-immunoreactive proteins via dopaminergic D1 receptors. Proc. Natl. Acad. Sci. USA 88, 1291-1295. 